\title{
Comparison of Numerical Models of Impact Force for Simulation of Earthquake-Induced Structural Pounding
}

\author{
Robert Jankowski \\ Faculty of Civil and Environmental Engineering, Gdańsk University of Technology, \\ ul. Narutowicza 11/12, 80-952 Gdańsk, Poland \\ jankowr@pg.gda.pl
}

\begin{abstract}
Structural pounding during earthquakes is a complex phenomenon involving plastic deformations, local cracking, etc. The aim of the present paper is to check the accuracy of three pounding force numerical models, such as: the linear viscoelastic model, the non-linear elastic model following the Hertz law of contact and the non-linear viscoelastic model. In the analysis, the results of numerical simulations have been compared with the results of an impact experiment conducted by dropping balls of different building materials. The results of the study indicate that the non-linear viscoelastic model is the most precise one in simulating the pounding force time history during impact.
\end{abstract}

Keywords: pounding, earthquakes, impact force, numerical simulation.

\section{Introduction}

Earthquake-induced pounding between neighbouring, inadequately separated buildings or bridge segments can lead to considerable damage or even collapse of colliding structures (see, for example, [1,2]). Impact itself is a highly complex phenomenon involving plastic deformations at contact points, local cracking or crushing, friction, etc. what results in difficulty in its modelling. Structural pounding has been recently intensively studied applying different numerical models of impact force. The fundamental study on pounding between buildings in series using a linear viscoelastic model has been conducted by Anagnostopoulos [3]. Jankowski et al. [4] used the same model to study pounding of superstructure segments in bridges. In order to simulate the force-deformation relation more realistically, a non-linear elastic model following the Hertz law of contact has been adopted by a number of researchers (see, for example, [5,6]). For the purposes of a more precise simulation of a physical phenomenon, a non-linear viscoelastic model has also been considered [79]. In this model, a non-linear spring following the Hertz law of contact is applied together with an additional non-linear damper, which is activated during the approach period of collision in order to simulate the process of energy loss taking place mainly during that period.

The aim of the present paper is to check the accuracy of these pounding force models for the purposes of simulation of different building materials impacts. In the 
analysis, the results of numerical simulations have been compared with the results of an impact experiment conducted by dropping balls of different mass.

\section{Pounding Force Numerical Models}

\subsection{Linear Viscoelastic Model}

The linear viscoelastic model is the most frequently used one for simulation of structural pounding under earthquake excitation (see, for example, [3,4]). The pounding force during impact, $F(t)$, for this model is expressed as:

$$
F(t)=k \delta(t)+c \dot{\delta}(t)
$$

where $\delta(t)$ describes the deformation of colliding structural members, $\dot{\delta}(t)$ denotes the relative velocity between them, $k$ is the impact element's stiffness simulating the local stiffness at the contact point and $c$ is the impact element's damping, which can be obtained from the formula [3]:

$$
c=2 \xi \sqrt{k \frac{m_{1} m_{2}}{m_{1}+m_{2}}},
$$

where $m_{1}, m_{2}$ are masses of structural members and $\xi$ is the damping ratio related to a coefficient of restitution, $e$, which accounts for the energy dissipation during impact [10]. Value of $e=1$ deals with the case of a fully elastic collision, value of $e=0$ with a fully plastic one. The relation between $\xi$ and $e$ in the linear viscoelastic model is given by the formula [3]:

$$
\xi=\frac{-\ln e}{\sqrt{\pi^{2}+(\ln e)^{2}}}
$$

\subsection{Non-linear Elastic Model}

In order to model the pounding force-deformation relation more realistically, a nonlinear elastic model following the Hertz law of contact has been adopted by a number of researchers [5,6]. The pounding force, $F(t)$, for this model is expressed by the formula:

$$
F(t)=\beta \delta^{\frac{3}{2}}(t)
$$

where $\beta$ is the impact stiffness parameter, which depends on material properties and geometry of colliding bodies. The disadvantage of the Hertz contact law model is that it is fully elastic and does not account for the energy dissipation during contact due to plastic deformations, local crushing, etc. 


\subsection{Non-linear Viscoelastic Model}

For the purposes of a more precise simulation of an impact phenomenon, a non-linear viscoelastic model has been proposed [7]. The pounding force, $F(t)$, for this model is expressed by the formula:

$$
\begin{array}{lll}
F(t)=\bar{\beta} \delta^{\frac{3}{2}}(t)+\bar{c}(t) \dot{\delta}(t) & \text { for } \dot{\delta}(t)>0 & \text { (approach period), } \\
F(t)=\bar{\beta} \delta^{\frac{3}{2}}(t) & \text { for } \dot{\delta}(t) \leq 0 & \text { (restitution period), }
\end{array}
$$

where $\bar{\beta}$ is the impact stiffness parameter and $\bar{c}(t)$ is the impact element's damping, which at any instant of time can be obtained from the formula [7]:

$$
\bar{c}(t)=2 \bar{\xi} \sqrt{\bar{\beta} \sqrt{\delta(t)} \frac{m_{1} m_{2}}{m_{1}+m_{2}}},
$$

where $\bar{\xi}$ denotes the damping ratio related to a coefficient of restitution, $e$. The approximate relation between $\bar{\xi}$ and $e$ in the non-linear viscoelastic model is expressed by the formula [11]:

$$
\bar{\xi}=\frac{9 \sqrt{5}}{2} \frac{1-e^{2}}{e(e(9 \pi-16)+16)} .
$$

\section{Comparison of Pounding Force Numerical Models}

In order to verify the accuracy of pounding force models for the use of different building materials, the results of the numerical simulations have been compared with the results of an impact experiment conducted by dropping steel, concrete and timber balls of different mass on rigid surface. Balls have been dropped from various height levels in order to obtain different impact velocities. The properties of balls used in the experiment are specified in Table 1. The experimental setup is shown in Fig. 1.

Table 1. Properties of balls used in the experiment

\begin{tabular}{lcc}
\hline Material & Ball diameter $(\mathrm{mm})$ & Ball mass $(\mathrm{kg})$ \\
\hline \multirow{2}{*}{ Steel } & 21 & $0.053-0.054$ \\
(type 18G2A) & 50 & $0.538-0.541$ \\
& 83 & 2.013 \\
\hline \multirow{2}{*}{ Concrete } & 103 & $1.329-1.350$ \\
(grade C30/37) & 114 & $1.763-1.835$ \\
& 128 & $2.531-2.636$ \\
\hline \multirow{2}{*}{ Timber (pinewood) } & 55 & $0.065-0.066$ \\
& 71 & $0.109-0.112$ \\
& 118 & $0.493-0.497$ \\
\hline
\end{tabular}




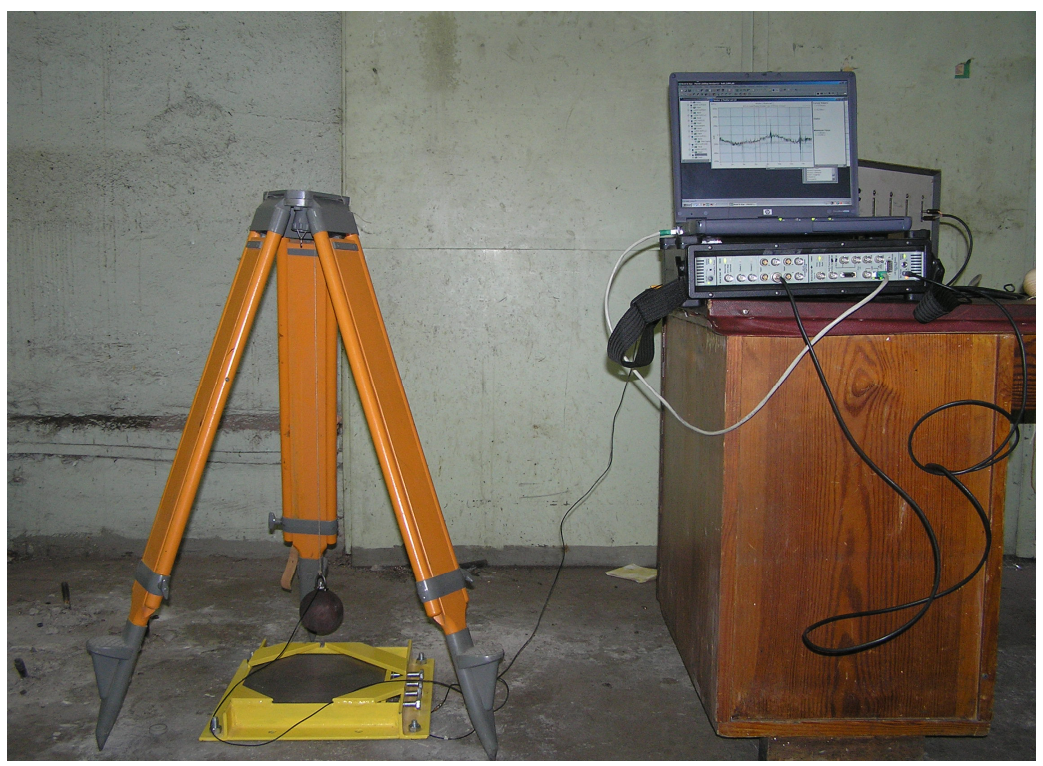

Fig. 1. Setup of the experiment

The numerical analysis has been conducted using the following equation of motion:

$$
m \ddot{y}(t)+F(t)=m g,
$$

where $m$ is mass of a ball, $\ddot{y}(t)$ its vertical acceleration and $g$ stands for the acceleration of gravity. The pounding force, $F(t)$, has been set to zero when $y(t) \leq h$ ( $h$ is a drop height) and has been calculated according to Equation (1), (4) or (5) when $y(t)>h$, whereas the deformation, $\delta(t)$, has been calculated as:

$$
\delta(t)=y(t)-h
$$

A time-stepping integration procedure with constant time step $\Delta t=1 \times 10^{-6} \mathrm{~s}$ has been applied to solve the Equation (8) numerically. The values of the impact stiffness parameters: $k, \beta$ and $\bar{\beta}$, defining the models used in the numerical analysis, have been determined using the method of the least squares. The difference between the results of the experiment and the results of the numerical analysis has been assessed by calculating the normalised error:

$$
E=\frac{\|\mathbf{F}-\overline{\mathbf{F}}\|}{\|\mathbf{F}\|} \cdot 100 \% .
$$

where $\mathbf{F}$ is an impact time history vector obtained from the experiment, $\overline{\mathbf{F}}$ is an impact time history vector obtained from the numerical analysis and $\|\mathbf{F}-\overline{\mathbf{F}}\|$ is an Euclidean norm of $\mathbf{F}-\overline{\mathbf{F}}$. 
The experimental study and the numerical analysis have been conducted for a large number of impact cases. In the following sections of this paper, the examples of the results are presented.

\subsection{Steel-to-Steel Impact}

In the first example, the results of the numerical analysis are compared with the results of the experiment conducted for a steel ball of mass $2.013 \mathrm{~kg}$ impacting the steel surface with the velocity of $0.92 \mathrm{~m} / \mathrm{s}$. In the numerical analysis, the following values of parameters defining the different pounding force models have been used: $k=4.82 \times 10^{8} \mathrm{~N} / \mathrm{m}, \quad \xi=0.17(e=0.58)$ for the linear viscoelastic model, $\beta=7.55 \times 10^{10} \mathrm{~N} / \mathrm{m}^{3 / 2}$ for the non-linear elastic model and $\bar{\beta}=6.60 \times 10^{10} \mathrm{~N} / \mathrm{m}^{3 / 2}$, $\bar{\xi}=0.49(e=0.58)$ for the non-linear viscoelastic model. The pounding force time history measured during the experiment and the histories received from the numerical analysis for the considered example of steel-to-steel impact are presented in Fig. 2. Using Equation (10), the simulation errors for pounding force histories have been calculated as equal to: $15.9 \%$ for the linear viscoelastic model, $64.1 \%$ for the nonlinear elastic model and $15.3 \%$ for the non-linear viscoelastic model.

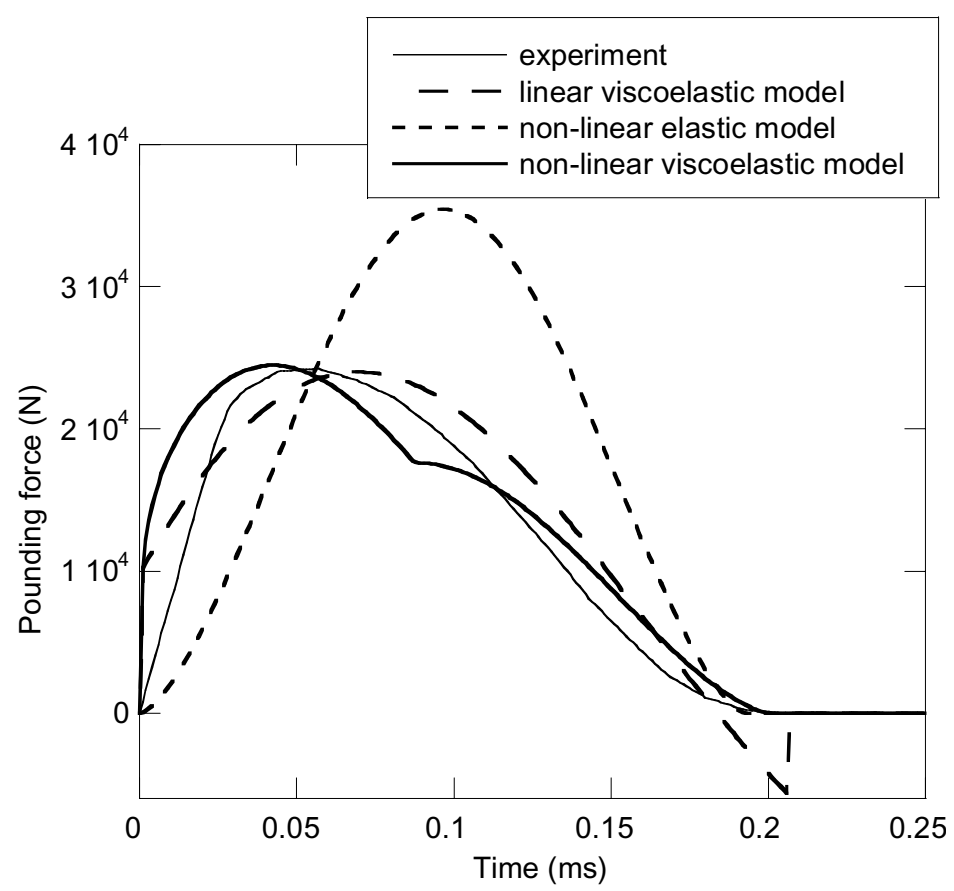

Fig. 2. Pounding force time histories for steel-to-steel impact 


\subsection{Concrete-to-Concrete Impact}

The second example concerns the comparison between the results of the numerical simulations and the experiment conducted for a concrete ball of mass $1.763 \mathrm{~kg}$ impacting the concrete surface with the velocity of $0.13 \mathrm{~m} / \mathrm{s}$. In the numerical analysis, the following values of parameters defining the different pounding force models have been used: $k=4.91 \times 10^{7} \mathrm{~N} / \mathrm{m}, \xi=0.09 \quad(e=0.76)$ for the linear viscoelastic model, $\beta=1.04 \times 10^{10} \mathrm{~N} / \mathrm{m}^{3 / 2}$ for the non-linear elastic model and $\bar{\beta}=1.02 \times 10^{10} \mathrm{~N} / \mathrm{m}^{3 / 2}, \bar{\xi}=0.22 \quad(e=0.76)$ for the non-linear viscoelastic model. The pounding force time history measured during the experiment and the histories received from the numerical analysis for the considered example of concrete-toconcrete impact are presented in Fig. 3. The simulation errors for pounding force histories from Fig. 3 have been calculated as equal to: $12.7 \%$ for the linear viscoelastic model, $33.5 \%$ for the non-linear elastic model and $11.6 \%$ for the nonlinear viscoelastic model.

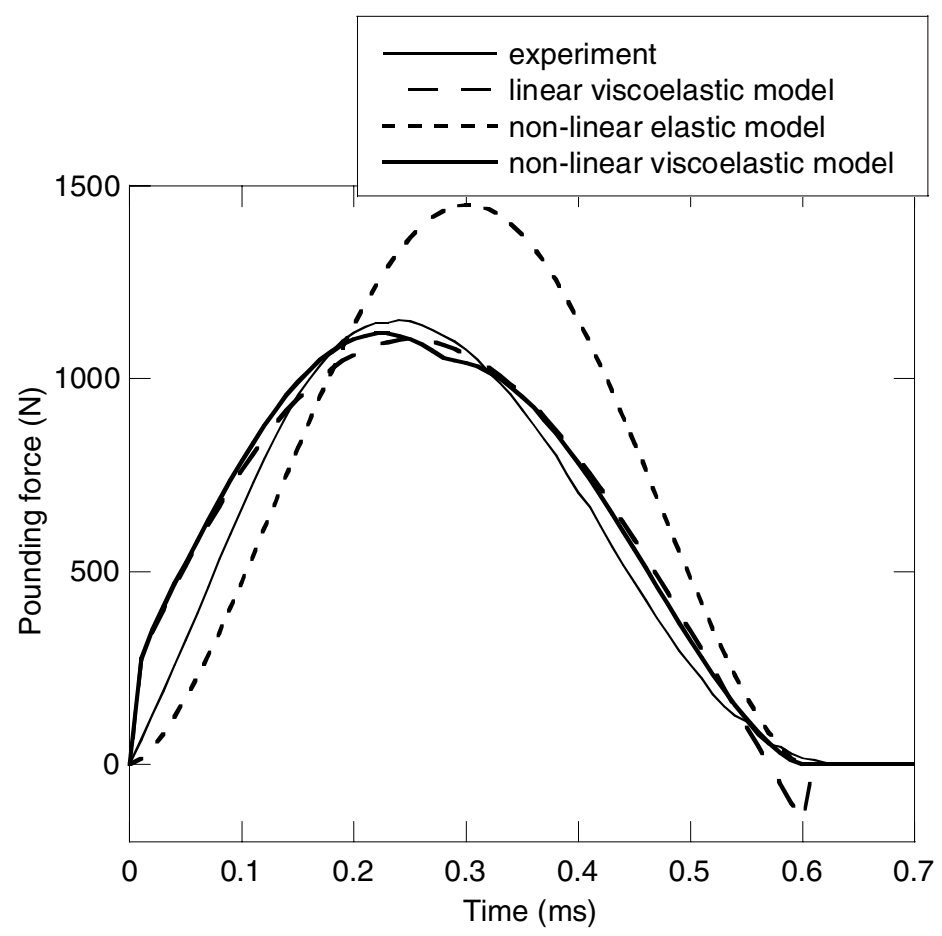

Fig. 3. Pounding force time histories for concrete-to-concrete impact

\subsection{Timber-to-Timber Impact}

In the third example, the results of the numerical analysis are compared with the results of the experiment conducted for a timber ball of mass $0.109 \mathrm{~kg}$ impacting the 
timber surface with the velocity of $0.39 \mathrm{~m} / \mathrm{s}$. In the numerical analysis, the following values of parameters defining the different pounding force models have been used: $k=2.28 \times 10^{6} \mathrm{~N} / \mathrm{m}, \quad \xi=0.16 \quad(e=0.61) \quad$ for the linear viscoelastic model, $\beta=3.24 \times 10^{8} \mathrm{~N} / \mathrm{m}^{3 / 2}$ for the non-linear elastic model and $\bar{\beta}=2.52 \times 10^{8} \mathrm{~N} / \mathrm{m}^{3 / 2}$, $\bar{\xi}=0.43(e=0.61)$ for the non-linear viscoelastic model. The pounding force time history measured during the experiment and the histories received from the numerical analysis for the considered example of timber-to-timber impact are presented in Fig. 4. Using Equation (10), the simulation errors for pounding force histories have been calculated as equal to: $20.9 \%$ for the linear viscoelastic model, $61.0 \%$ for the non-linear elastic model and $19.5 \%$ for the non-linear viscoelastic model.

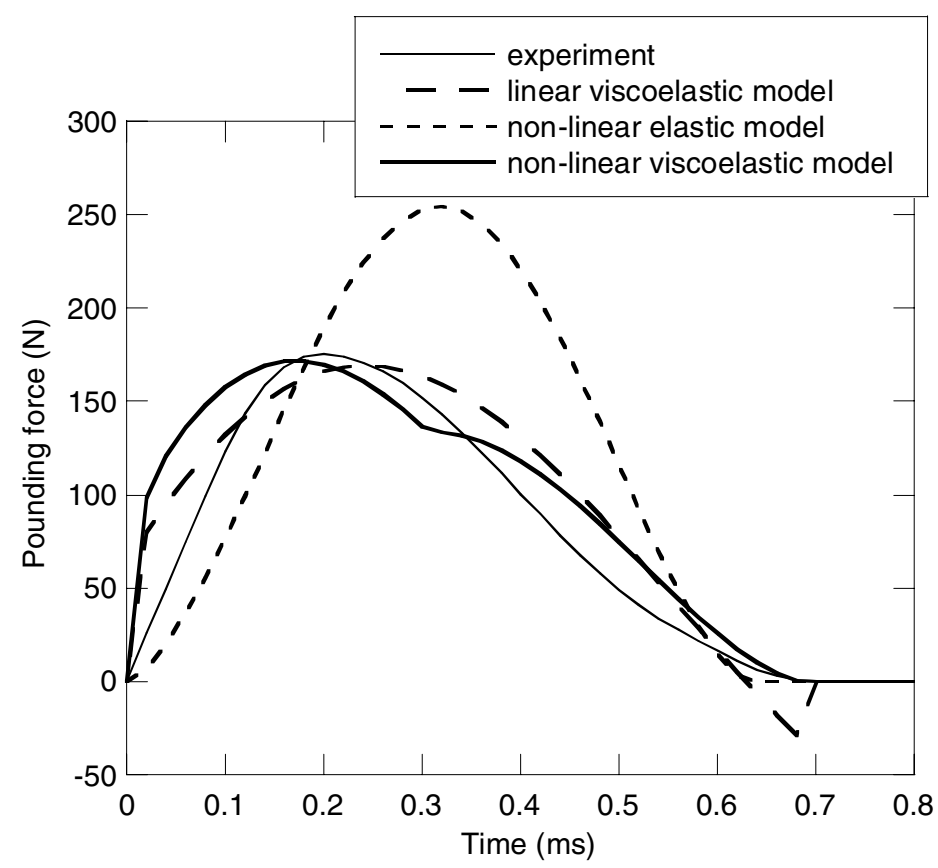

Fig. 4. Pounding force time histories for timber-to-timber impact

\section{Conclusions}

The results of the study indicate that the non-linear viscoelastic model is the most precise one in simulating the pounding force time histories during impact for three different building materials. The model allows us to simulate the relatively rapid increase in the pounding force during the approach period of collision and the decrease in the force with lower unloading rate during the restitution period. Because of the above the model can be successfully used for the numerical simulations of pounding-involved response of structures under earthquake excitation in order to 
enhance the accuracy of the analysis. On the other hand, Figs. 2-4 show the drawbacks of the two other models considered. In the case of the linear viscoelastic model, the negative force can be observed just before separation, which does not have any physical explanation. In the case of the non-linear elastic model following the Hertz contact law, the pounding force history at approach and restitution periods is symmetric, due to elastic behaviour, and a maximum pounding force attains a higher value in comparison with the experimental results.

\section{References}

1. Rosenblueth, E., Meli, R.: The 1985 earthquake: causes and effects in Mexico City. Concrete international 8, 23-34 (1986)

2. Kasai, K., Maison, B.: Building pounding damage during the 1989 Loma Prieta earthquake. Engineering Structures 19, 195-207 (1997)

3. Anagnostopoulos, S.A.: Pounding of buildings in series during earthquakes. Earthquake Engineering and Structural Dynamics 16, 443-456 (1988)

4. Jankowski, R., Wilde, K., Fujino, Y.: Pounding of superstructure segments in isolated elevated bridge during earthquakes. Earthquake Engineering and Structural Dynamics 27, 487-502 (1998)

5. Jing, H.-S., Young, M.: Impact interactions between two vibration systems under random excitation. Earthquake Engineering and Structural Dynamics 20, 667-681 (1991)

6. Chau, K.T., Wei, X.X.: Pounding of structures modeled as non-linear impacts of two oscillators. Earthquake Engineering and Structural Dynamics 30, 633-651 (2001)

7. Jankowski, R.: Non-linear viscoelastic modelling of earthquake-induced structural pounding. Earthquake Engineering and Structural Dynamics 34, 595-611 (2005)

8. Jankowski, R.: Impact force spectrum for damage assessment of earthquake-induced structural pounding. Key Engineering Materials 293-294, 711-718 (2005)

9. Jankowski, R.: Pounding force response spectrum under earthquake excitation. Engineering Structures 28, 1149-1161 (2006)

10. Goldsmith, W.: Impact: The theory and physical behaviour of colliding solids. Edward Arnold Ltd., London (1960)

11. Jankowski, R.: Analytical expression between the impact damping ratio and the coefficient of restitution in the non-linear viscoelastic model of structural pounding. Earthquake Engineering and Structural Dynamics 35, 517-524 (2006) 